\title{
ASYMPTOTIC BEHAVIOR OF RETARDED DIFFERENTIAL EQUATIONS
}

\author{
CHEH-CHIH YEH \\ Department of Mathematics \\ Central University \\ Chung-Li, Taiwan \\ Republic of China
}

(Received November 15, 1985)

ABSTRACT. Some integral criteria for the asymptotic behdvior of oscillatory solutions of higher order retarded differential equations are given.

KEY WORDS AND PHRASES. Retarded differential equations, oscillation. 1980 AMS SUBJECT CLASSIFICATION CODE. 34K15.

1. INTRODUCTION.

Recently, Tong [1] proved the following interesting result.

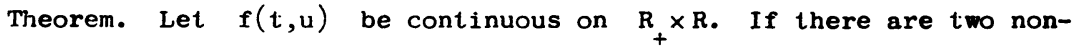
negative continuous functions $v(t), p(t)$ for $t \geqslant 0$, and a continuous function $g(u)$ for $u \geqslant 0$ such that

(a) $\int_{1}^{\infty} v(t) p(t) d t<\infty$.

(b) $g(u)$ is positive and nondecreasing for $u>0$,

(c) $|f(t, u)| \leqslant v(t) p(t) g\left(t^{-1}|u|\right)$ for $t \geqslant 1, u \in R$, then the equation

$$
u^{\prime \prime}+f(t, u)=0
$$

has solutions which are asymptotic to $a+b t$, where $a, b$ are constant and b $\neq 0$.

In this note we generalize Tong's result to a more general case which improves also the results of Chen and Yeh [2] and Kusano and Singh [3]. Using this result, we establish an asymptotic behavior of oscillatory solutions of retarded differential equations.

2. MAIN RESULTS.

Consider the following retarded differential equations

$$
L_{n} y(t)+f(t, y(g(t)))=h(t), \quad t \geqslant 0, \quad n \geqslant 2
$$

where $L_{n}$ is an operator defined by 


$$
\begin{aligned}
& L_{0} y(t):=\frac{y(t)}{r_{0}(t)}, \quad L_{i} y(t):=\frac{1}{r_{i}}(t) \frac{d}{d t} L_{i-1} y(t), \quad i=1,2, \cdots, n \\
& r_{n}(t):=1 .
\end{aligned}
$$

Here $r_{i}(t) \in C^{n-i}\left[R_{+}, R\right]$ with $r_{i}(t)>0$ for $i=0,1, \cdots, n-1$.

Sufficient smoothness to guarantee the existence of solutions of (2.1) on an infinite subinterval of $R_{+}$will be assumed without mention. The following conditions are assumed to hold in this note.

(i) $f \in C\left[R_{+} \times R, R j\right.$ and there exist two positive functions $p(t), H(t)$ $\epsilon \mathrm{C}\left[\mathrm{R}_{+}, \mathrm{R}_{+}\right]$with $\mathrm{H}(\mathrm{t})$ nondecreasing and $k H(t) \leqslant \mathrm{H}(k \mathrm{t})$ for any $k>0$ such that

$$
|\mathbf{f}(\mathrm{t}, \mathrm{u})| \leqslant \mathrm{p}(\mathrm{t}) \mathrm{H}(|\mathrm{u}|),
$$

(ii) $g, h \in C\left[R_{+}, R\right], \quad g(t) \leqslant t, \lim _{t \rightarrow \infty} g(t)=\infty$,

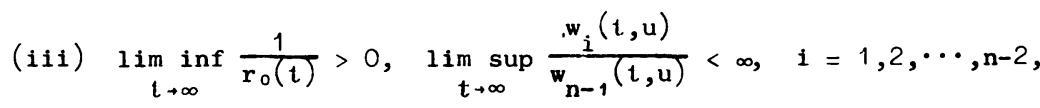

where $w_{i}(t, u)$ is defined by

$$
w_{i}(t, u):=\int_{u}^{t} r_{1}\left(s_{1}\right) \int_{u}^{s_{1}} r_{2}\left(s_{2}\right) \cdots \int_{u}^{s_{i-1}} r_{i}\left(s_{i}\right) d s_{i} \cdots d s_{2} d s_{1} .
$$

Theorem 1. Let

$$
\int_{n-1}^{\infty} w_{n}(t) p(t) d t<\infty
$$

$$
\int^{\infty} \ln (\mathrm{l}) \mid \mathrm{dt}<\infty
$$

hold. If $y(t)$ is a solution of $(2.1)$, then $y(g(t))=O\left(w_{n-1}(t, T)\right)$ for some $T \geqslant 0$.

Proof. Let $y(t)$ be a solution of $(2.1)$ on an interval $\left[T_{0}, \infty\right), T_{0} \geqslant 0$. It follows from (ii) and (iii) that there exist $a \quad T \geqslant T_{0}$ and a positive constant $m$ such that

$$
g(t) \geqslant T_{0} \text { for } t \geqslant T
$$

and

$$
\inf _{t \geqslant T} \frac{1}{r_{0}(t)}=\frac{1}{m} \text {. }
$$

By (iii), there is a positive constant c such that

$$
w_{i}(t, T) \leqslant w_{n-1}(t, T), \quad i=1,2, \cdots, n-2 .
$$

Now a simple argument shows that

$$
\begin{aligned}
& \frac{|y(g(t))|}{m} \leqslant\left|L_{0} y(g(t))\right| \leqslant \sum_{i=0}^{n-1}\left|L_{i} y(T)\right| w_{i}(g(t), T) \\
& \quad+\int_{T}^{g(t)} r_{1}\left(s_{1}\right) \int_{T}^{s_{1}} r_{2}\left(s_{2}\right) \cdots \int_{T}^{s_{n-2}} r_{n-1}\left(s_{n-1}\right) \int_{T}^{s_{n-1}}\left|L_{n} Y(s)\right| d s d s_{n-1} \cdots d s_{1}
\end{aligned}
$$




$$
\leqslant c w_{n-1}(t, T) \sum_{i=0}^{n-1} L_{i} y(T)+w_{n-1}(t, T) \int_{T}^{t}\left|L_{n} y(s)\right| d s .
$$

Hence

$$
\begin{aligned}
\frac{\operatorname{ly}(g(t)) \mid}{w_{\Omega-1}(t, T)} & \leqslant c m \sum_{i=0}^{n-1}\left|L_{i} y(T)\right|+m \int_{T}^{t}|h(s)| d s+m \int_{T}^{t} p(s) H(y(g(s))) d s \\
& \leqslant M+m \int_{T}^{t} w_{n-1}(s, T) p(s) H\left(\frac{\operatorname{ly}(g(s))}{w_{n-1}(s, T)}\right) d s,
\end{aligned}
$$

where

$$
M:=c m \sum_{i=0}^{n-1}\left|L_{i} y(T)\right|+m \int_{T}^{\infty} \ln (s) \mid d s .
$$

By Bihari's inequality [4] or LaSalle's inequality [5] we have

$$
\frac{|y(g(t))|}{w_{n-1}(t, T)} \leqslant G^{-1}\left(G(M)+\int_{T}^{t} w_{n-1}(s, T) p(s) d s\right) \text {, }
$$

where $G(x):=\int_{T}^{x} \frac{d t}{H(t)}$ and $G^{-1}(x)$ is the inverse function of $G(x)$. This and (2.2) imply $\frac{\operatorname{ly}(g(t)) \mid}{w_{n-1}(t, T)}$ is bounded. This completes the proof.

Remark 1. For $n=2, \quad r_{0}(t)=r_{1}(t)=1$ and $g(t)=t$, Theorem 1 improves Tong 's result [1].

Remark 2. For $H(u)=|u|^{r}$, where $r \in(0,1]$, Theorem 1 improves the results of Chen and Yeh [2, Theorem 1] and Singh and Kusano [3, Theorem 1] which require the condition

$$
\int^{\infty} r_{i}(t) d t=\infty, \text { for } i=1,2, \cdots, n-1 .
$$

Using Theorem 1, we can prove the following theorem which extends Theorem 3 of Philos [6].

Theorem 2. Let (2.2) and (2.3) hold. Assume that for some $T \geqslant 0$ (2.4) $\int_{T}^{\infty} r_{1}\left(s_{1}\right) \int_{s_{1}}^{\infty} r_{2}\left(s_{2}\right) \cdots \int_{s_{n-2}}^{\infty} r_{n-1}\left(s_{n-1}\right) \int_{s_{n-1}}^{\infty} p(s) H\left(c w_{n-1}(s, T)\right) d s d s_{n-1} \cdots d s_{1}$

$$
<\infty
$$

for any constant $c>0$, and

$$
\int_{T}^{\infty} r_{1}\left(s_{1}\right) \int_{s_{1}}^{\infty} r_{2}\left(s_{2}\right) \cdots \int_{s_{n-2}}^{\infty} r_{n-1}\left(s_{n-1}\right) \int_{s_{n-1}}^{\infty}|h(s)| d s d s_{n-1} \cdots d s_{1}<\infty
$$

hold. Then every oscillatory solution $y(t)$ of (2.1) satisfies

$$
\lim _{t \rightarrow \infty} L_{i} y(t)=0 \text { for } 1=1,2, \cdots, n-1 \text {. }
$$

The proof of Theorem 2 is essentially the same as that of Theorem 3 in [6], so we omit the details.

Example 1. The differential equation

$$
\left(t y^{\prime}(t)\right)^{\prime}+\frac{1}{t} y(t)=\frac{2}{t^{2}}, \quad t \geqslant 1
$$


has an oscillatory solution $y(t)=\frac{1}{t}+\sin (1 n t)$ but $\lim _{t \rightarrow \infty} y(t)$ does not exist. In this example, condition (2.2) and (2.4) are not satisfied, while (2.3) and (2.5) are valid.

Example 2. Consider the differential equation

$$
\left(e^{-t} y^{\prime}\right) \prime+e^{-3 t-\pi} y(t-\pi)=e^{-2 t}\left[\sin t+7 \cos t-e^{-2 t} \sin t\right] \text {, }
$$

for $t \geqslant 0$. All conditions of Theorem 2 are satisfied. It has $y(t)=e^{-t} \sin t$ as an oscullatory solution which approaches zero as $\mathrm{t} \rightarrow \infty$.

ACKNOWLEDGEMENT. This paper is dedicated to Professor Shih-Ming Lee on his 70th birthday.

\section{REFERENCES}

1. Tong, J. The asymptotic behavior of a class of nonlinear differential equations of second order, Proc. Amer. Math. Soc. $\underline{4}$ (1982), 235-236.

2. Chen, L. S. and Yeh, C. C. Necessary and sufficient conditions for asymptolic decay of oscillations in delayed functional equations, Proc. Royal Soc. Edinburgh, 21A (1981), 135-145.

3. Kusano, T. and Singh, B. Asymptotic behavior of oscillatory solutions of a differential equation with deviating arguments, J. Math. Anal. Appl. 83 (1981), 395-407

4. Bihari, I. A generalization of a lemma of Bellman and its application to uniqueness problems of differential equations, Acta Math. Acad. Sci. Hungar. I (1956), 81-94.

5. LaSalle, J. P. Uniqueness theorems and successive approximations, Ann. Math. 50 (1949), 722-730.

6. Philos, C. G. Nonoscillation and damped oscillations for differential equations with deviating arguments, Math. Nachr. 106 (1982), 109-119. 


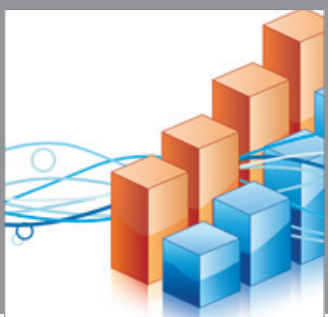

Advances in

Operations Research

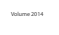

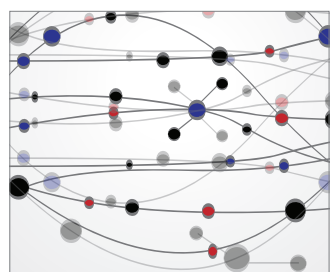

\section{The Scientific} World Journal
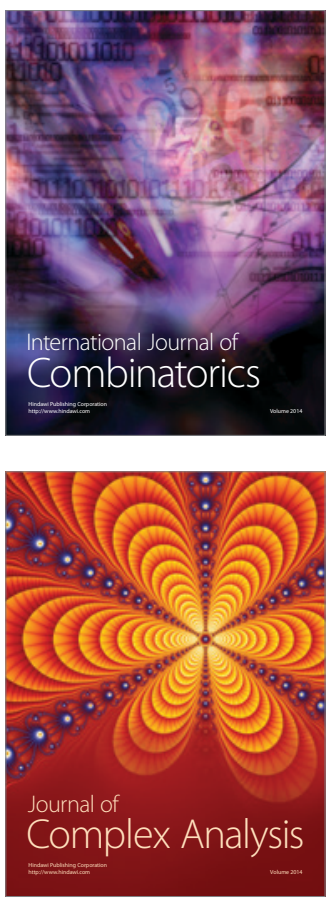

International Journal of

Mathematics and

Mathematical

Sciences
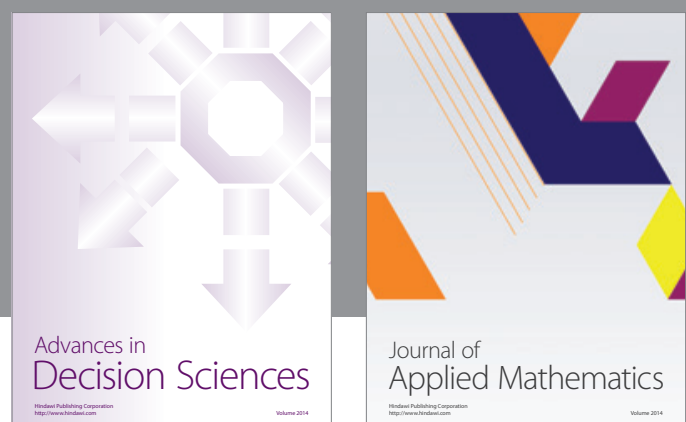

Journal of

Applied Mathematics
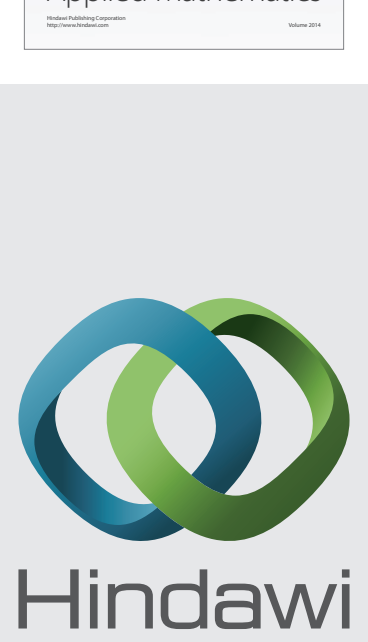

Submit your manuscripts at http://www.hindawi.com
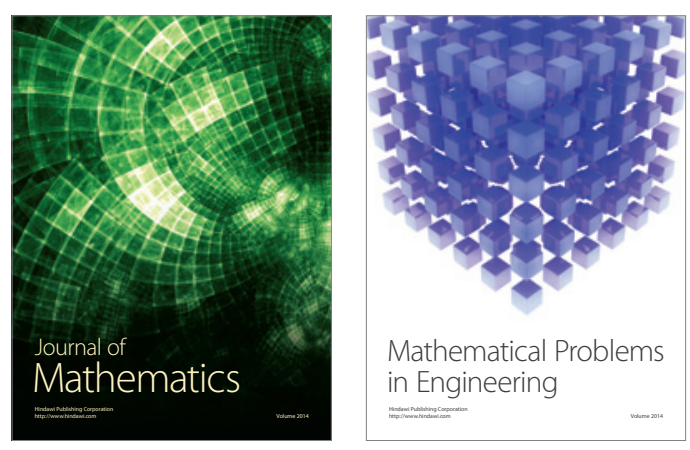

Mathematical Problems in Engineering
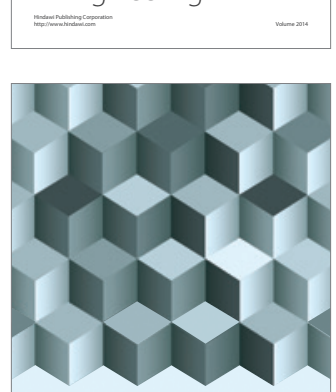

Journal of

Function Spaces
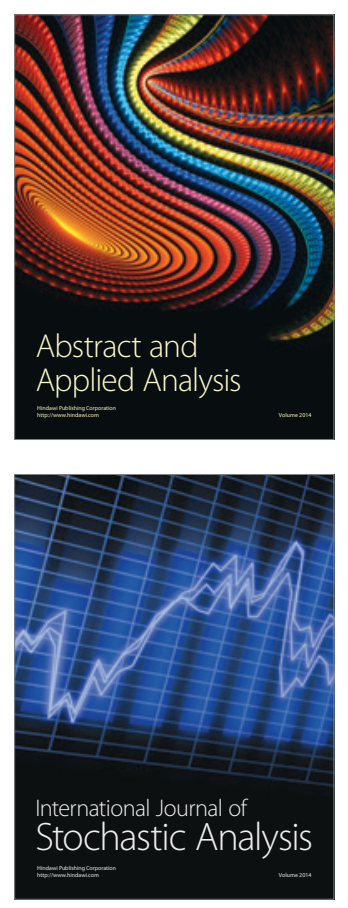

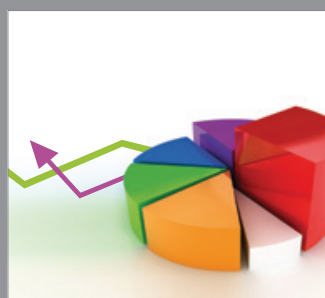

ournal of

Probability and Statistics

Promensencen
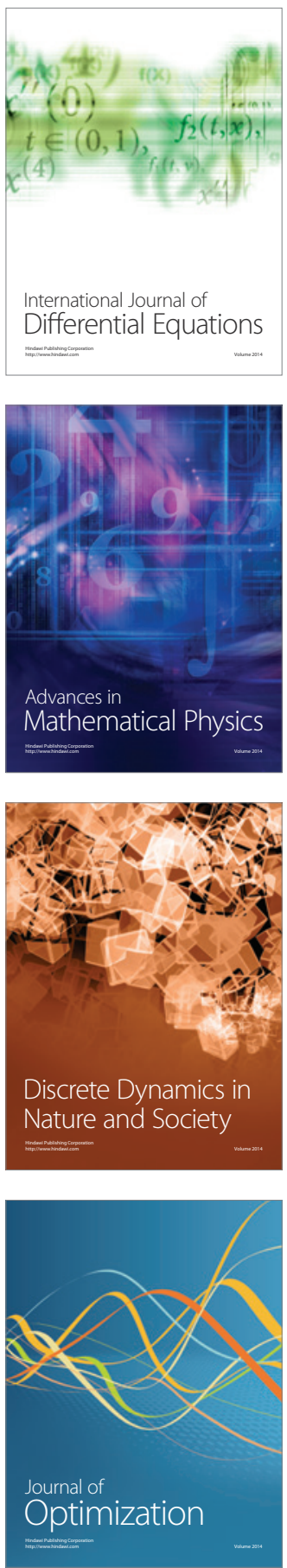